\title{
Geodatabase interpolation method development using GIS technology for changes regional assessment monitoring in hydrodynamic parameters of groundwater status in Syrdarya region
}

\author{
Ilkhom Ruziev", and Satbay Nurjanov \\ Tashkent Institute of Irrigation and Agricultural Mechanization Engineers, Tashkent, Uzbekistan
}

\begin{abstract}
In the Republic, especially in the Syrdarya region, the reclamation state of irrigated lands and soil salinization is inextricably linked with the level of groundwater, their salinity, and movement. The level of groundwater and its salinity depends largely on the technical condition of the drainage networks and the amount of atmospheric precipitation, the supply of fresh water during the vegetation period, and groundwater movement from outside. The future of using GIS in a different sphere is discussed. GIS gives possibilities to collect the data, renewing it, or use new information in the analysis. It requires a quick change of GIS information about Earth because procedures in the Earth are dynamically changeable. Periodically changing information in GIS gives us the possibility to get new information and analyze it. GIS technologies and techniques started using widely in all spheres of humanity. It is important to know its properties. The main and effective method of land reclamation is the construction of collector-drainage systems and the maintenance of groundwater level, preventing secondary salinization of land by irrigation and drainage water. GIS is currently widely used and implemented in agriculture and water management and land reclamation monitoring in Uzbekistan and all over the world. Data analysis and transmission and storage within the GIS are addressed in GIS.
\end{abstract}

\section{Introduction}

Development of Geographic Information System (GIS), the occurrence of salinization and waterlogging, crop extinction in the agricultural field, for a stable and high yield from agricultural crops, there must be an optimal combination of all the essential factors to the life of the plant. For the process of photosynthesis: the necessary moisture and nutrients in the soil; thermal energy of the atmosphere in the upper soil layer; water exchange should be provided to the surface [1].

\footnotetext{
*Corresponding author: ruziyevilhom@mail.ru
} 
The vast majority of irrigated agriculture in Uzbekistan are desert areas, where the lands have a certain amount of natural primary salinity, high mineralization, and close to the surface. Irrigated agriculture in these regions can only give us the expected results if it is done with scientifically sound reclamation measures [2].

Many models are created in GIS that are successfully used in water management of different countries of the world. Liu (2007) inserted EPIC model, which was suggested by FAO, into GIS and created GEPIC model (J. Liu, 2007; J. Liu, 2009) [3-4]. Stockholm Environmental Institute created WEAP (water evaluation and planning) model by GIS modeling (Assaf and Saadeh, 2008). Fortes et al. (2005) inserted the existing irrigation scheduling simulation model ISAREG (this model also calculates the waste water amount of the area by inserting natural and climatic factors) into GIS and created a GISAREG model based on the GIS mentioned above. This model predicted the quality of utilizing the Syr Darya basin water in different climatic scenarios. Creating this model in GIS eases the labour (Fortes, Platonov, and Pereira, 2005). From these models, SEBAL is the most widely spread model. Over 30 countries are implementing this model for water resource control [6-7].

Several works are carried out to determine the ameliorative condition of the irrigated lands: - study the groundwater movement and their impact on natural irrigation factors, determine their impact on natural irrigation factors, soil salinity, and other important environmental and saline measures. [7]. Development, monitoring of the technical condition of collector-drainage networks, repair of collector-drainage networks that require repair z timely repair of Nexis, produced counsel, farms and exploitation activities and controlled by the management of the district reclamation fulfillment.

The GIS (geographic information system) technology is being developed to improve GIS-based data analysis based on field experiments when assessing factors affecting land reclamation [8].

\section{Materials and Methods}

Therefore, the task of GIS is to receive, collect, analyze, store and transmit data in any format. Being able to access any of these data formats and accessing the program will further enhance GIS capabilities. The ability of GIS to conduct various statistical analyses, mapping, and creating various databases ensures that it is more relevant and popularized in land and water conservation [9]. Therefore, the task of GIS is to receive, collect, analyze, store and transmit data in any format. Accessing any of these data formats and accessing a meal program will further enhance GIS capabilities. The ability of GIS to conduct various statistical analyses, mapping, and creating various databases ensures that it is more relevant and popularized in land and water conservation [10].

Monitoring Using GIS in groundwater of Central Asia started to develop after 2000, after implementing water management in this region. To supply the integrated and regular water management, to create irrigation sets and objects, water users, vegetation type and area database and maps for regional and global scale, and analyze it rapidly was the main problem of water managers. During its long-time experiments, water management found an answer to this problem. It was using new computer technologies and scientific achievements for water management. This component was added to the Central Asian water management plan. As a result, the scope of work in this field expands [11].

GIS Digital Database Analysis and Database Creation Since the 1920s. Improvement of GIS and installation of personal computers started in the 1970s. Since the 1980s, scientists have begun to use GIS in natural and technical sciences. With each passing year, GIS began to improve and become more widely used in various industries, and the capabilities and content of the community began to grow. Upgrading capabilities and the program has 
increased its use in various areas. As can be seen from the above, using GIS in solving various problems increased 2.5 times from 2000 to 2015 [12-13].

GIS has been used for many years in agriculture and water management. Awulachew et al. (2012) note that the use of GIS in these areas enhances data accuracy and provides access to information about difficult-to-reach areas. Another advantage of meliorative hydrogeological monitoring of irrigated lands based on GIS technologies is the achievement of automation and centralization of management, remote data acquisition, and management of facilities. Automatic data transmission is achieved. Creating a unified water and land surveillance system and establishing a centralized system is currently the main task of the GIS sector [15].

We have the following advantages when monitoring the reclamation of irrigated lands based on GIS technologies: [3-4].

Creation of the analysis database to the user in the format he wants

Creation and use of agricultural and hydrological models [11].

Creating Surface Water Models [12].

Creating models of groundwater and surface water and their delivery systems [13];

Land use and classification models and maps [14];

Formation of water supply system plans [2];

Groundwater management modeling;

Water quality monitoring

Hazardous Material Mapping and Modeling, Natural Hazards or Groundwater Management [5];

\section{METHODS AND TECHNIQUES}

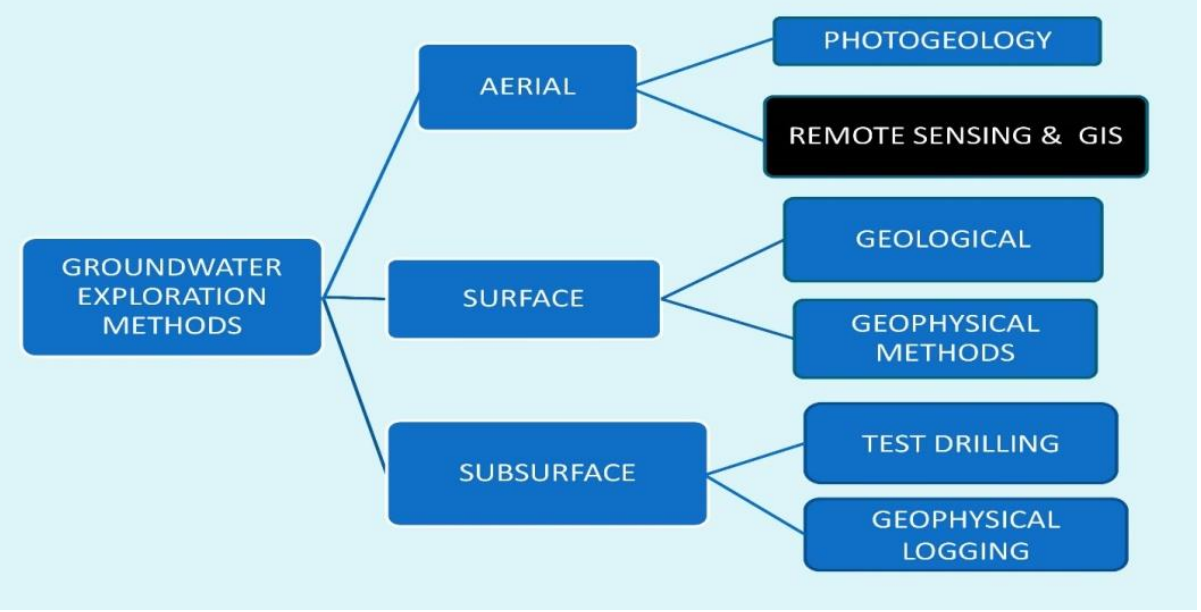

Fig. 1. Application of remote sensing and GIS in groundwater

\section{Results and Discussion}

The need to integrate various methods with Remote Sensing (RS) and Geographical Information System (GIS) techniques to increase accuracy in water exploration is undeniable. Spatial observation of the translation of effluent rivers to influent rivers as the flow across the crystalline rock-sedimentary rock contact (CRSRC) led to the incorporation of contact proximity thematic layer into the GIS-based model for this research. RS Digital 
Elevation Model data was used to generate the thematic maps of slope, lineament, and elevation. In contrast, conventional maps were used to generate the thematic maps of soil, drainage density, and drainage proximity. Geological field mapping and ground trothing gave rise to the thematic maps of geology and contact proximity. The weighting of thematic layers was done by pair-wise comparison even as modeling was done using a weighted overlay technique in a GIS environment. Groundwater potential modeling of the area revealed three zones: low potential zone coinciding with rugged and high relief areas; medium potential zone coinciding with areas on the crystalline basement with lower relief; and high potential zone, which occur in the sedimentary terrain within the study area. In terms of the areal extent, the low, medium, and high groundwater potential zones cover 249, 391, and 130 square kilometers, respectively. Groundwater potential map agrees reasonably with field conditions. However, the need for drillers, including government agencies, to keep data such as pumping tests is recommended to aid in validating models like this.

Many scientists have created SEBAL models to control irrigation in the Khorezm region and Fergana valley in central Asia. Here SEBAL models are used with MODIS images (Chemin et al., 2004; Bohovic, 2009; Awan et al., 2011; Bohovic et al., 2012; Awan, 2015). Especially, scientific research of Conrad is very important in this field. He created the SEBAL model using images of RS, MODIS, ASTER, SPOT-5, and other satellites for the $\mathrm{S}$ basin and calculated the fertility of utilizing water. Besides, he created several hydrologic models for the very area by using GIS.

The use of GIS in agriculture, irrigation networks, and meliorative hydrogeological monitoring of irrigated land has a high potential for monitoring the use of irrigation networks and agricultural land (Tsihrintzis et al., 1996). The following features and equipment make GIS the most important program in agriculture (Zhang, 2005):

- Spatial analysis;

- 3D operations

- Network layers;

- Short way to summarize;

- Simple data reception;

- Accessibility options;

- Duration of the process;

- Determining closer distances;

-Visualization.

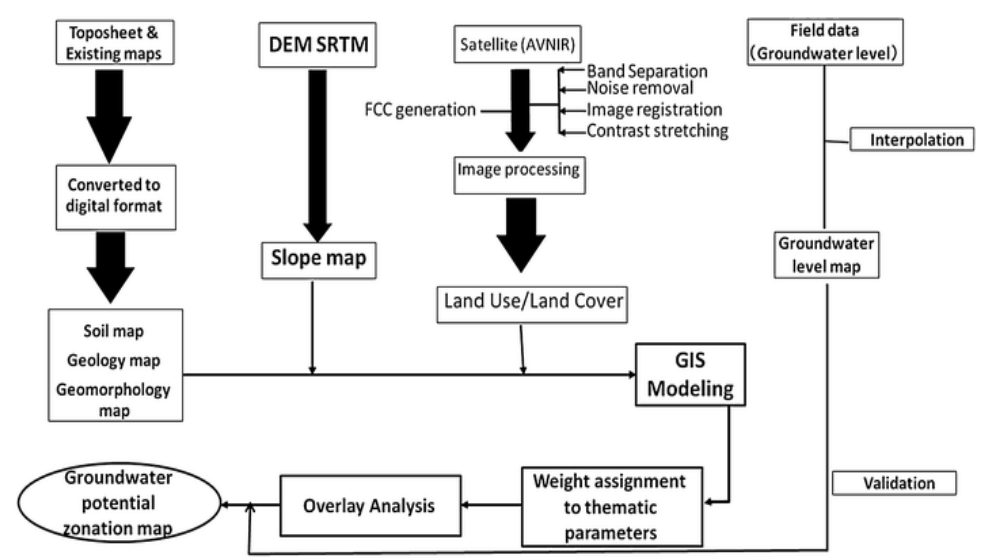

Fig. 2. Mapping of groundwater potential zones in Syrdarya area 


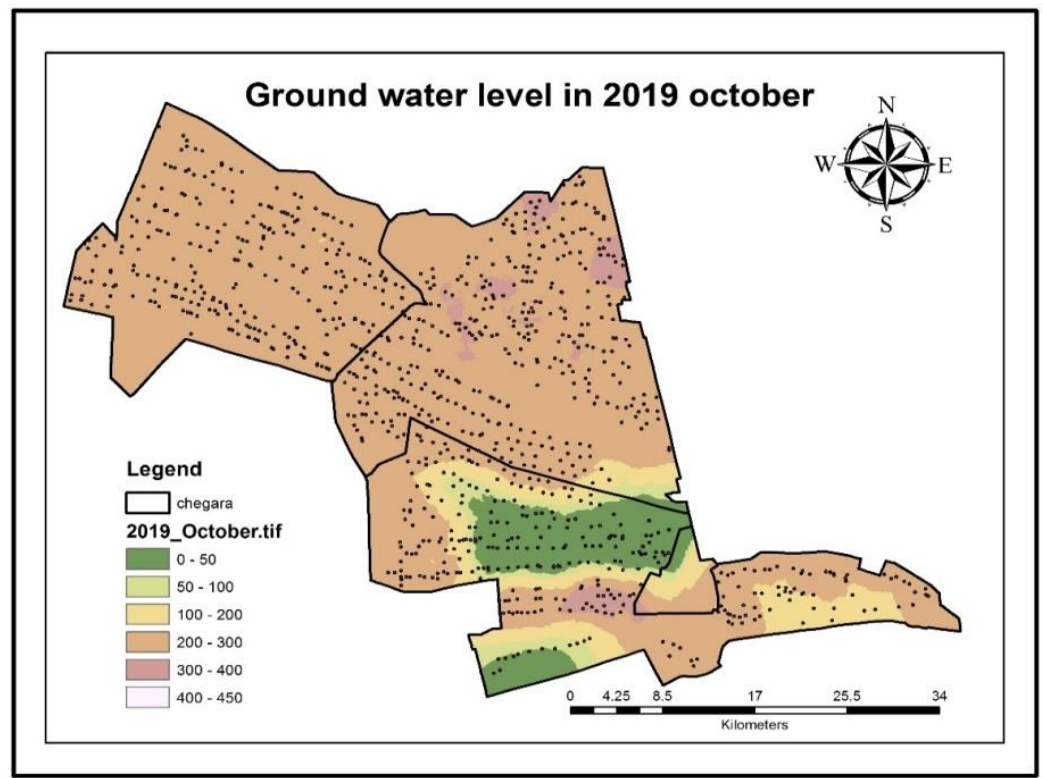

Fig. 3. Mapping groundwater recharge potential zone using a GIS

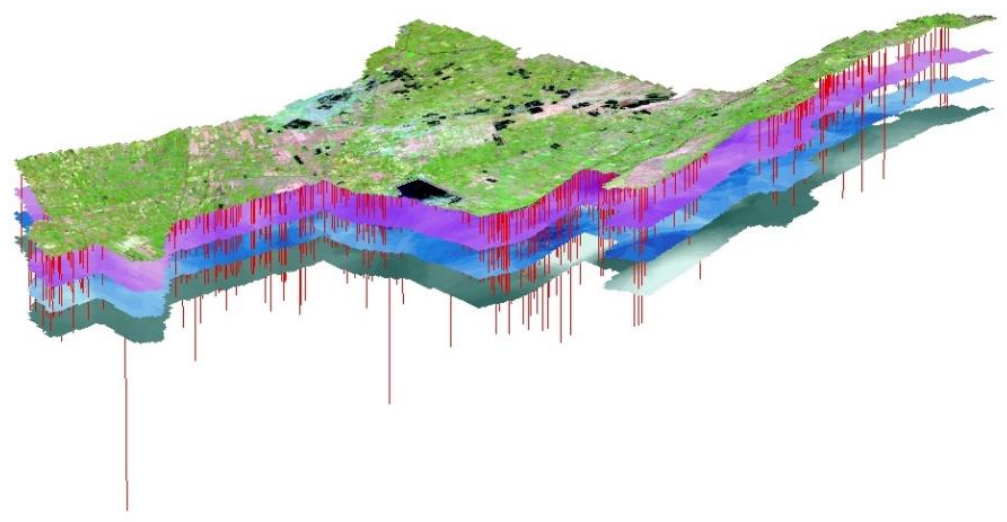

Fig. 3. 3D operations Mapping groundwater recharge potential zone using a GIS

\section{Conclusions}

The introduction of GIS in some arid regions and improve water resource management by this system can be an innovation for some regions. But, GIS is just software, and for processing and obtaining solutions, one needs to collect data and enter results of analysis. This program becomes a useful data source for us. Data collection and entering it into GIS are also highly diversified and based on many selections. There are many ways and methods to collect data. Consequently, the types of data are numerous. Filling GIS with unnecessary information causes the user to be lost in a huge information mess. Therefore, it is essential in research to get only necessary data and choose proper analysis software for it.

There are 286,500 hectares of irrigated land in the region controlled by the Syrdarya Amelioration Expedition. Thus, as of October 1, 2017, the soil samples were analyzed by 
the Dynamic Chemical Experts at a constant dynamic point, and the amount of chlorine ion was determined by the amount of silver nitrate and by the $\mathrm{X}$-express and conductor apparatus. Soil samples were taken from layers 0-0.3 m, 0.3-0.7 m, 0.7-1.0 m. [3]

According to the results, as of October 1, 2017, the area of 7059 saline areas, 223727 low salinity, 50222 moderately saline, and 5486 strong saline areas were identified. The area under saline decreased by 616 hectares compared to 2013, the area of low salinity decreased by 1,036 hectares, the average saline area increased by 211 hectares, and the saline area increased by 1,441 hectares.

The geographical information system (GIS) has been developed with detailed data on these indicators and maps of soil salinity categories by region.

Strongly saline areas have been increased in Sardoba, Havas, and Mirzaabad districts. These areas are the areas prone to salinity. The recent establishment of fish farms in Mirzaabad, Havas, and Sardoba districts, inadequate water supply during the irrigation season, pumping water from the drainage networks, resulting in increased saline areas. [4]

Current leaching measures for the 2017 crop are set at the low-salinity area of 56,430 ha, moderately saline at 1,095 ha, and heavily saline area at 1,675 ha, and the full-scale leaching has been performed in the designated areas.

An analysis of the autumn 2013 and spring 2017 shows that the average salinity area in all areas of the region increased due to the decrease in the area of saline and saline areas.

\section{References}

1. Ames, Daniel P., Eric B. Rafn, Robert Van Kirk, and Benjamin Crosby. "Estimation of Stream Channel Geometry in Idaho Using GIS-Derived Watershed Characteristics." Environmental Modelling \& Software 24 (3): pp.444-448. (2009).

2. Aspinall, Richard, and Diane Pearson. 2000. "Integrated Geographical Assessment of Environmental Condition in Water Catchments: Linking Landscape Ecology, Environmental Modelling and GIS." Journal of Environmental Management 59 (4): pp.299-319.

3. Assaf, Hamed, and Mark Saadeh. 2008. "Assessing Water Quality Management Options in the Upper Litani Basin, Lebanon, Using an Integrated GIS-Based Decision Support System." Environmental Modelling \& Software 23 (10): 1327-1337.

4. Awan, Usman Khalid. "Coupling Hydrological and Irrigation Schedule Models for the Management of Surface and Groundwater Resources in Khorezm, Uzbekistan." Accessed June 17. (2015).

5. Awan, Usman Khalid, Bernhard Tischbein, Christopher Conrad, Christopher Martius, and Mohsin Hafeez. "Remote Sensing and Hydrological Measurements for Irrigation Performance Assessments in a Water User Association in the Lower Amu Darya River Basin." Water Resources Management 25 (10): 2467-2485. (2011).

6. Awulachew, Seleshi Bekele. 2012. The Nile River Basin: Water, Agriculture, Governance and Livelihoods. Routledge.

7. Banerjee, Shweta, Vishakha Sakhare, and Rahul Ralegaonkar.. "Application of ArcGIS for E-Governance of Rural Water management." (2013).

8. Bhaduri, Budhendra, Jon Harbor, Bernie Engel, and Matt Grove. (2014). "Assessing Watershed-Scale, Long-Term Hydrologic Impacts of Land-Use Change Using a GISNPS Model." Environmental Management 26 (6): 643-58. doi:10.1007/s002670010122.

9. Bohovic, Roman. 2009. "Of the Thesis: Modeling Evapotranspiration at Different Scales."

10. Bohovic, Roman, and others. Modelling Evapotranspiration at Different Scales: By the Means of Remote Sensing. LAP LAMBERT Academic Publishing. (2012). 
11. Burkhard, Benjamin, Franziska Kroll, Stoyan Nedkov, and Felix Müller. 2012. "Mapping Ecosystem Service Supply, Demand and Budgets." Ecological Indicators, Challenges of sustaining natural capital and ecosystem servicesQuantification, modelling \& valuation/accounting, 21 (October): 17-29. doi:10.1016/j.ecolind.(2011).

12. Chemin, Yann, Alexander Platonov, Mehmood UI-Hassan, and Iskandar Abdullaev. (2004). "Using Remote Sensing Data for Water Depletion Assessment at Administrative and Irrigation-System Levels: Case Study of the Ferghana Province of Uzbekistan." Agricultural Water management 64 (3): 183-196.

13. Conrad, Christopher, Sebastian Fritsch, Julian Zeidler, Gerd Rücker, and Stefan Dech. 2010. "Per-Field Irrigated Crop Classification in Arid Central Asia Using SPOT and ASTER Data." Remote Sensing 2 (4): 1035-1056.

14. Ficklin, Darren L., Yuzhou Luo, Eike Luedeling, and Minghua Zhang. "Climate Change Sensitivity Assessment of a Highly Agricultural Watershed Using SWAT." Journal of Hydrology 374 (1): 16-29. (2009).

15. G Yusupov, I Ruziev, S Nurjanov On the establishment of the correlation dependence of results of physical properties, dynamic probing and filtration coefficient from the granulometric composition of alluvial sands in the valley of the Amudarya river IOP Conference Series: Materials Science and Engineering (2021) 356883012035 19-31. 